Penultimate draft. Please cite final draft forthcoming in CHEST

\title{
THE CONDITIONS FOR ETHICAL APPLICATION OF RESTRAINTS
}

Parker Crutchfield, PhD; Tyler S Gibb, JD, PhD; Michael J Redinger, MD; Dan Ferman; John Livingstone, MD

Despite the lack of evidence for their effectiveness, the use of physical restraints for patients is widespread. The best ethical justification for restraining patients is that it prevents them from harming themselves. We argue that even if the empirical evidence supported their effectiveness in achieving this aim, their use would nevertheless be unethical, so long as well known exceptions to informed consent fail to apply. Specifically, we argue that ethically justifiable restraint use demands certain necessary and sufficient conditions. These conditions are that the physician obtain informed consent for their application, that their application be medically appropriate, and that restraints be the least liberty-restricting way of achieving the intended benefit. It is a further question whether their application is ever medically appropriate, given the dearth of evidence for their effectiveness.

\section{INTRODUCTION}

Restricting a person's physical movement is a significant infringement upon a person's liberty. Physically restraining patients therefore puts healthcare providers at risk of committing a serious moral wrong by infringing on a patient's liberty to move his or her body. Yet not all restraints are unethical. In this paper we detail the conditions for the ethical use of physical restraints in medicine. While most research on the use of physical restraints has focused on prevalence, outcomes, and alternatives, very little of this research has provided guidance on the conditions under which physically restraining a patient is ethical. Others have argued that the principles of biomedical ethics sometimes permit the use of restraints and other times prohibit

their use; and some have offered similar recommendations. ${ }^{1,2}$ But this previous research, and to 
Penultimate draft. Please cite final draft forthcoming in CHEST

our knowledge any other research, fails to thoroughly defend the conditions under which restraints are permissible. What follows fills that gap.

In the first section we briefly discuss research on the prevalence of and reasons for the use of restraints. This research indicates widespread use of physical restraints and for a diverse range of reasons and under a diverse range of conditions. In the second section we begin to evaluate the reasons for using restraints on patients. In the subsequent sections we consider the conditions for permissible liberty restrictions, the outcomes of physically restraining patients, and available alternatives to physical restraints. We conclude that in the absence of informed consent from the patient or their surrogate, the use of physical restraints is an impermissible violation of the patient's liberty. This conclusion rests on the idea that the movement of one's

body, specifically, one's arms — which restraints are intended to prevent — is a basic liberty, the restriction of which cannot be justified by typical exceptions to obtaining informed consent.

\section{PREVALENCE}

The use of restraints in hospitals is widespread, especially in ICUs. For example, one study found that $82 \%$ of ICUs in France had more than $50 \%$ of their mechanically ventilated patients in physical restraints. ${ }^{3}$ But France is not unique. In Europe $33 \%$ of all ICU patients are restrained. ${ }^{4}$ In the Netherlands $23 \%$ of all ICU patients are restrained. ${ }^{5}$ And in South Africa nearly half (48\%) of all ICU patients are restrained. ${ }^{6}$

In the United States, 50 of every 1000 patient days are spent physically restrained. ${ }^{7}$ This amounts to around 27,000 patients restrained daily. Unsurprisingly, 56\% of these are in ICUs. In medical intensive care units 179 of every 1000 patient days are spent in restraints, while in 
Penultimate draft. Please cite final draft forthcoming in CHEST

surgical intensive care units and neuro-intensive care units restraints are even more prevalent (220 days and 268 days, respectively). While restraints are widely used in some places, some nations, like the United Kingdom and Scandinavian countries, prohibit the use of restraints. Frequent restraint use occurs despite universal agreement among practice standards, professional bodies, and regulatory bodies that restraints should be used sparingly and reassessed regularly. ${ }^{8-}$

\section{REASONS}

Reasons for restraining patients vary. But the most common reason, and the reason that most justifies the use of restraints, is that restraints purportedly prevent the patient from removing a device, such as an endotracheal tube, which would cause the patient harm. Often restraints are applied to patients who are agitated, restless, or delirious. But they are also applied as a precautionary measure. For example, some ICUs have a practice that all intubated patients be physically restrained, unless they are sufficiently chemically restrained.

Another reason for restraints is staff safety. For instance, agitated patients are a potential threat to the safety of the nursing staff, and restraining patients may mitigate this threat. A third reason for physical restraints is that restraining patients is convenient for the staff. ${ }^{16-19}$ In some cases, this restriction of liberty is convenient to facilities incapable or unwilling to staff medical units appropriately. In other cases, the patient rooms are not convenient to the location of the nurses' station to allow for appropriate, less restrictive supervision of intubated patients.

The case that a patient ought to be restrained rests on the premises that (a) restraints prevent device removal and (b) that the removal of a device constitutes a harm to the patient. As 
Penultimate draft. Please cite final draft forthcoming in CHEST

we argue below, neither of these premises are adequately supported. More generally, however, the argument that a patient ought to be restrained is a consequentialist argument: the ends (harms associated with patient-removal of devices) justify the means (the restriction of a basic liberty). But the act of applying restraints is ethical only if the ends are actually achieved and there are no overwhelming costs associated with the means.

\section{EXCEPTIONS TO INFORMED CONSENT}

The freedom to control one's body is a basic liberty. It's difficult to overstate the importance of the question: Under what circumstances is it permissible for anyone (i.e., healthcare providers, governments, law enforcement, etc.) to restrict a person's basic liberty of uninhibited physical movement? And does restraining patients violate their autonomy? Answers to these questions help to define the boundaries of permissibly restraining patients.

We seek to protect a patient's autonomy because to protect their autonomy is to respect them as a person. Medicine expresses this value of autonomy by emphasizing shared decisionmaking between physician and patient and through thorough processes of informed consent. Restraints, like any treatment, violate a person's autonomy unless the patient or their surrogate has provided informed consent or the requirement for informed consent is excepted.

There are several well known exceptions to the requirement for obtaining informed consent. One is that informed consent is not necessary for treatment of medical emergencies. But restrained patients are not typically in need of emergent treatment - they're usually applied after the emergency has passed. The emergency exception also justifies the compelled treatment of people who are an emergent threat to themselves or others. If a person is a threat to themselves 
Penultimate draft. Please cite final draft forthcoming in CHEST

or others, but that threat is distant, then it is impermissible to compel treatment (indeed, we are all a distant threat to ourselves or others).

It is also unnecessary to obtain informed consent from patients who have waived this requirement for themselves. Restrained patients may have explicitly waived this right, or they may not. If they have, then consent for physical restraints is unnecessary. For example, some patients write advance directives for mental health. In these the patient may explicitly waive the right to consent (or refuse) various treatments. In these cases, obtaining consent for treatments in the advance directive is unnecessary.

A third exception is therapeutic privilege. Therapeutic privilege is invoked when obtaining informed consent is medically contraindicated - the informed consent process would harm the patient. While it's true that restraints are applied to prevent harm, and that obtaining informed consent may cause the patient or their surrogate to refuse the application of the restraints, therapeutic privilege cannot exempt a physician from obtaining informed consent. Therapeutic privilege is justifiably invoked only when the process of obtaining informed consent harms the patient, not when obtaining informed consent merely makes the patient or their surrogate less likely to receive recommended treatment.

We argue elsewhere for a fourth exception: informed consent is unnecessary when obtaining it would undermine the achievement of something objectively valuable. ${ }^{20}$ But this exception offers no harbor for those wanting to apply restraints without informed consent, as obtaining informed consent for restraints would not undermine the achievement of something objectively valuable. 
Penultimate draft. Please cite final draft forthcoming in CHEST

The standard exceptions to the requirement for obtaining informed consent don't exempt physicians from obtaining informed consent for restraints. Although all treatments require a patient's consent, sometimes this consent can be presumed. For example, a physician treating a patient in an ICU may presume consent for standard treatments such as dosage or medication changes, or for treatments implied by other treatments that the patient has consented to. Might consent for restraints be presumed?

\section{RESTRICTING BASIC LIBERTIES}

The liberty to move one's body in the way one wants is a basic liberty. Often discussions of which liberties are basic will wave at things like liberty of thought, association, and speech. But one could equally hold that moving one's body, in this case the liberty to move one's arms, is a basic liberty. We think this claim is so obvious it doesn't need defense. But for those wanting such a defense, Phillip Pettit argues that a liberty is basic when it is required for living the life of a free person. ${ }^{21}$ Moving one's functioning arms seems to count as required for living the life of a free person. Though obviously humans flourish without arms, when arms function as they should a person cannot be considered free if the movement of their arms is physically restricted. A person with fully functioning arms living a life with those arms chained is not a free person. Provided that one's arm movements don't encroach on another person's liberties, the liberty to move one's arms in the way one wants is a basic liberty.

There are circumstances in which it is ethically and legally permissible to restrict a person's basic liberties. These circumstances include when the state punishes one for crimes committed. Prisoners have some of their basic liberties revoked (but they retain others). 
Restricting a person's basic liberties may also be permissible when the person retaining that liberty represents a preventable threat to another person or him or herself, such as when one expresses suicidal or homicidal ideation, or even when laws compel behavior, such as in a person's compulsion to get vaccinated or wear a seatbelt. In these cases, the threat of potential harm (and the likelihood of potential benefit) justifies the liberty restriction. However, even in the case of involuntary commitment the restriction of basic liberties proceeds only under rigorous regulatory protections. A third instance of permissible restriction of basic liberties is when the person whose liberties are being restricted explicitly consents to their restriction.

The liberty to move one's arms is sufficiently important that reasonable people could find that treatment requiring its restriction conflicts with their own values. Reasonable people may think that retaining basic liberties is more valuable than attempting to improve their own health. The decision to restrict one's liberty is not something about which physicians know more. Basic liberty restriction is not in the medical school curriculum, unlike which antibiotic is better for the detected bacteria or which analgesic is compatible with patient susceptibility, which are medical decisions consent for which can be presumed. An unconscious ICU patient has little say in whether it is appropriate to discontinue vancomycin, but they (along with the state) have the final say in whether it is appropriate to restrict their basic liberties.

Consent can be permissibly presumed only for treatments that a reasonable person wouldn't refuse. A person may reasonably refuse restraints at the cost of experiencing some other harm. Indeed, frequently patients who may recover medically from some condition choose instead to die, because losing their liberty is so costly to them. Further, seeking treatment does not imply consent to all medically necessary treatments. There is no such thing as an ethical general consent to all treatment upon presentation to a hospital. A patient presenting to the 
hospital for unremitting back pain unknowingly caused by end-stage bone cancer doesn't thereby consent to multiple rounds of chemotherapy. A person seeking medical treatment is unlikely to know what the burdens of treatment are until the physician informs them. Once they find out, they may find that the burdens of treatment outweigh the benefits and decide to refuse the recommended treatment. There is no liberty more basic to medicine than the liberty a competent and capable patient has to refuse recommended treatments. Our point is simply that a reasonable person may find that the restriction of their basic liberties diminishes their well being so significantly that the liberty restriction represents a burden too great to bear. Physicians cannot presume consent for restraints.

Relatedly, one might claim that the restriction of one's basic liberty to move one's arms is permissible on the grounds that it is necessary for the prevention of harm to oneself or others. First, however, typically liberty restrictions proceed through the legal system with due process protections; the application of restraints does not. Second, the conclusion requires the premises that the person's retaining the liberty is likely to result in harm, and that this harm is prevented by the use of restraints. Given the results of empirical research, we ought to be skeptical of both of these premises.

\section{OUTCOMES}

Restraints are typically applied to prevent the patient from removing a device and causing harm to themselves. The premise that restraints prevent device removal is questionable. The research on the benefits and burdens of restraints is, at best, equivocal. ${ }^{19,22-24}$ Studies indicate that physical restraints often fail to prevent device self-removal and instead that they may 
contribute to increased rates of self-removal. ${ }^{25-33}$ Conversely, evidence indicates that the harms associated with self-removal are exaggerated. Others have highlighted an extensive number of harms from physical restraints, including physical harm to patient up to and including death, as well as patient, family, and nursing psychological distress. ${ }^{31,34-50}$ Moreover, in countries with minimal restraint use, simple interventions such as staff educational and environmental changes have been found to decrease restraint use without evidence in increased patient or staff risk. ${ }^{25,56-}$ 62

The evidence casts doubt upon the position that restraining patients prevents device removal and the associated harm. It can't be taken for granted that restraints prevent device removal - to claim that it does requires evidence, and the proponent of using restraints bears this burden of proof.

The argument that a patient ought to be restrained rests on the premises that that the person's retaining the liberty is likely to result in harm, and that this harm is prevented by the use of restraints. But these premises cannot be assumed - they must be supported with evidence. We are not claiming that restraints don't prevent device removal or that harm doesn't result from device removal. We are claiming that the evidence warrants skepticism of these premises sufficient to shift the burden of proof.

\section{PERMISSIBLE RESTRAINTS}

The evidence does not support the claim that restraints prevent patients from harming themselves. But there are further costs associated with their use. Not only does being restrained increase the likelihood of self-extubation, restrained patients are also more likely to experience 
Penultimate draft. Please cite final draft forthcoming in CHEST

distress, anxiety, nightmares, PTSD, perception of unethical behavior, and re-traumatization. For the patient, restraints are often perceived as traumatic. ${ }^{58-60}$ Patients are not the only people who may experience negative outcomes from restraints; nurses often feel guilt or regret for the application of restraints. ${ }^{61}$

The circumstances in which it is permissible to restrict a person's basic liberties do not obtain in the case of applying restraints to patients. And the circumstances in which they are usually applied are not exempt from the requirement of obtaining informed consent. Thus, restraints for which informed consent has not been obtained unjustifiably restrict a patient's basic liberties and violate the patient's autonomy. These are the greatest costs of using restraints.

There are, however, circumstances in which the application of restraints is ethically permissible. Although the application of restraints without informed consent cannot be justified by prevention of harm to the patient, restraints may be permissible if the patient or the patient's surrogate decision maker consent to their application. This is a necessary condition, not a sufficient one.

The restraints must also be medically appropriate. The evidence demonstrating the ineffectiveness of restraints calls into doubt the medical appropriateness of restraints. But it's possible that a physician may make a judgment that restraints are medically appropriate. Even if the physician makes such a judgment and the patient or their surrogate offers informed consent for their application, they may nevertheless be unethical.

If a treatment is medically appropriate, then the benefits of that treatment for the patient are proportional to the burdens. If they are disproportionate, then the treatment is not medically appropriate. Having one's liberty restricted is a great burden regardless of whether one consents and whether one values their own liberty. Having to bear this burden may threaten the 
proportionality, depending on the expected benefit of being restrained. If there are other ways of achieving the intended benefit (e.g., preventing self-extubation), then the burden of restraints is an unnecessary burden. And treatments that require patients to bear unnecessary burdens are not medically appropriate. If the same aim can be achieved with a different intervention, such as closer monitoring of the patient, that doesn't require the patient to bear such great burdens of liberty restriction, then that's the treatment that achieves the best proportion of benefits to burdens. Indeed, requiring a patient to bear unnecessary burdens may itself constitute harm. Thus, for restraints to be ethical they must be the least liberty-restricting means of achieving that aim.

These are the severally necessary and jointly sufficient conditions for the ethical application of restraints: the patient or surrogate must provide informed consent; the restraints must be medically appropriate; and the restraints must be the least liberty-restricting means of achieving the intended aim. These conditions allow for the ethical use of restraints in some cases, though the challenge to the physician will be to demonstrate that they are medically appropriate. But the conditions also prohibit the use of restraints simply for the purposes of staff convenience. Suppose that a nurse applies restraints because the patient cannot be closely monitored due to the fact that hospital will not financially support more nurses in the unit. In this case, there are other ways of preventing device removal, such as by placing a sitter in the room, which is less libertyrestricting. Thus, the use of restraints to prevent device removal is ethically unjustifiable.

Consider, for example, how these conditions would apply to common clinical situations. Suppose that an intubated patient whose life is being sustained by additional treatments begins pulling at the tubes and lines. At first, unless restraints are the least restrictive option and the patient has provided informed consent, they are ethically impermissible, even if they are 
medically appropriate. However, if other, less liberty-restricting options of preventing the selfremoval of life-sustaining devices fail, then restraints may become the least liberty restricting option. That they are the least restrictive means of preventing self-removal of devices does not obviate consent from the patient or surrogate. If consent for the treatment was not obtained beforehand (e.g., prior to a surgery), then it must be obtained prior to the application of restraints. To claim that consent is not required for their application in this case, one must provide reasons to think that the application of restraints is excepted from the requirement of informed consent. One possibility is that in such a case the emergency exception would apply. But if it does not, and if other exceptions don't apply, then it is unethical to apply restraints, even if the patient continues to remove devices, just as it would be unethical to compel any other treatment for which a patient or surrogate has not consented.

Consider a situation in which a patient is on $100 \%$ oxygen, proned on 20 PEEP, and will likely die if he pulls his endotracheal tube out. There are situations in which it may be ethically permissible to restrain the patient even if the patient or his surrogate has not consented to their application. These are situations in which the restraints are not only medically appropriate but also the least liberty-restricting means of preventing his death from self-extubation. If the restraints are emergently needed, then the satisfaction of these two conditions is sufficient for their ethical application, as there is no requirement for informed consent. That is, in situations in which restraints are emergently needed to save life or limb, consent for their application is not necessary. Satisfaction of the other two conditions is sufficient.

Suppose next that a patient has provided informed consent for cardiac catheterization but during the procedure becomes delirious and tries to grab the catheter. Such a patient is at risk of harming himself. The emergency exception may obviate informed consent for restraints in this 
case, but it would have been better to include the possibility of restraints in the original informed consent. Basic liberty restriction is an adverse event, as it can significantly diminish a patient's well being. If it is a risk of a procedure, as it would be in this case, then it ought to be included in the informed consent for the cardiac catheterization. For example, the informed consent ought to have included discussion of the fact that the patient may be at risk of delirium and that, if delirious, the patient may be restrained (the other two conditions would still have to also be satisfied). That it has been ignored in this process does not license physicians to ignore it altogether, in the absence of some exception to the requirement of informed consent.

Finally consider a case in which a patient's self-extubation is a nuisance, but not lifethreatening. In this case, the three conditions for ethical application of restraints apply: the patient or surrogate must provide informed consent; they must be medically appropriate; and they must be the least liberty-restricting means of achieving the intention at which they are aimed.

Often patients in an ICU are unable to offer informed consent because they lack decisional capacity and no other family member or friend or guardian is available to make medical decisions on the patient's behalf. Though there are often policies, procedures, and laws that assist in identifying surrogates, this often takes long periods of time, in some cases weeks. In the interim, the responsibility of medical decision making falls to the physician until another surrogate decision maker can be identified. In the likely event that the physician is unfamiliar with the patient's values and beliefs, he or she ought to make medical decisions according to the patient's best interests. But this standard of surrogate decision making doesn't warrant the unconsented application of restraints, for in the absence of knowledge of the patient's values and 
beliefs a physician can't assume that a patient's interests are best served by the promotion of their health rather than their retention of basic liberties.

There are likely many who would be uncomfortable with the conclusion that it is wrong to restrain a patient without their consent, especially given the prevalence of the practice. They might point to their own personal experience in which a person desperately trying to remove a breathing tube must be restrained. The natural objection such people might make is to the empirical evidence used above. Such a person might point out that the evidence that restraints don't prevent harm is inconclusive or, even after their own analysis of the studies, assert that the designs are flawed or that they don't support the inferences we say they support.

First, the fact that a person is trying to remove a medical device is evidence that, all things considered, the person wants that device removed, if that patient has decisional capacity. To assume that such attempts require restraints to prevent device removal is to assume that the patient is irrational, which is sometimes a false assumption. Second, we are not claiming that the empirical evidence refutes the claim that restraints prevent harm. We are saying it is compelling enough to shift the burden onto the proponent of using unconsented restraints. She must show that they do prevent harm. Furthermore, the fact that the empirical evidence doesn't support the use of restraints greases the wheels of our argument; it doesn't turn them. What turns the wheels is the fact that restraints are typically used in situations to which the standard exceptions to informed consent don't apply. And because the liberty to move one's arms is a basic liberty, one cannot presume consent to restrict it. Third, even if restraints did prevent harm, that doesn't excuse their unconsented use. We routinely allow people to make decisions that result in their own harm. If we didn't, hospitals wouldn't allow patients to leave the hospital against medical advice or refuse life-prolonging treatment. 
Penultimate draft. Please cite final draft forthcoming in CHEST

One might also object to the idea that moving one's arms is a basic liberty, and because it is not a basic liberty it is permissible to presume consent to restrict it. But this objection misses the mark. We haven't argued for the claim that only restriction of basic liberties requires informed consent. We hold that moving one's arms is a basic liberty and that restriction of any basic liberty requires informed consent, unless there is no such requirement, such as in emergencies or when the state has revoked the right to informed consent. This is compatible with the requirement that the restriction of non-basic liberties also be permissible only after obtaining informed consent. Indeed, it seems absurd to hold that presumed consent is sufficient for the restriction of non-basic liberties. If there are behaviors that can be permissibly limited simply at the will of others (the physician's presumption of consent), then those behaviors are not liberties at all. If physicians could presume consent for restriction of non-basic liberties, then the moment one establishes a physician-patient relationship the scope of one's liberties has narrowed significantly. Physicians are not empowered to restrict liberties, unless the state explicitly permits them to do so.

\section{ALTERNATIVES}

Using restraints on patients without obtaining informed consent is not ethically permissible, unless the standard exceptions to informed consent apply. But that doesn't mean that prevention of the purported harm is impossible. There are alternatives which can reduce the rate of unplanned extubation. ${ }^{62-65}$ These include mitts, efforts to minimize delirium (e.g., by maintaining the patient's appropriate sleep cycle), employing a sitter in the room with the patient, increasing the presence of family or other surrogate decision makers, using alarms on the 
beds or music in the room, increasing the number of nurses on the unit, and more frequently visiting the bedside in the evening and overnight. I

Physical restraints are not the only medical means of attempting to prevent device removal. Often chemical restraints are administered to prevent device removal. While the conditions for the permissibility of chemical restraints may be the same as those of the permissibility of physical restraints, we don't argue for this position here. Whether the conditions are the same hinges on whether chemical restraints restrict a person's liberty of thought, and whether such liberties are basic liberties. We don't offer an argument for these positions here, but recognize that our account may plausibly extend to chemical restraints.

\section{CONCLUSION}

The use of unconsented physical restraints on patients is not ethically permissible. They represent an impermissible restriction of a basic liberty. Even if they achieved their purported benefit — and there is little evidence that they do - their use still wouldn't be justified. But recall that there are other reasons, including safety to the staff, and staff convenience. Maintaining safety of the staff may justify short-term restraints (e.g., while sticking the patient with a needle or subduing a combative or violent patient). If a patient represents a long-term or permanent potential threat to the safety of the staff, then it is permissible to restrict the patient's basic liberties, but this ought to also proceed through a legal process designed to protect due process. For situations in which the above conditions are not satisfied, but nurses or physicians are nevertheless considering applying restraints, it is important that the team reflect on not only what might be gained by restraining a patient, but also what might be lost. More generally, given that 
Penultimate draft. Please cite final draft forthcoming in CHEST

nurses frequently request restraints but physicians order them and that the potential for ethical conflict is so great, it is important that interested parties engage in interprofessional dialogue regarding the conditions for the use of restraints. Ethics committees or hospital administrators may be in the best position to foster this dialogue.

What is most morally objectionable is to restrain patients for staff convenience. If a unit or facility cannot promote a patient's health without simultaneously violating their basic liberties, then it has no business caring for the sick.

\section{REFERENCES}

1. Moss RJ, Puma J La. The Ethics of Mechanical Restraints. Hastings Cent Rep. 1991;21(1):22. doi:10.2307/3563342.

2. Gastmans C, Milisen K. Use of physical restraint in nursing homes: clinical-ethical considerations. J Med Ethics. 2006;32(3):148-152. doi:10.1136/jme.2005.012708.

3. De Jonghe B, Constantin J-M, Chanques G, et al. Physical restraint in mechanically ventilated ICU patients: a survey of French practice. Intensive Care Med. 2013;39(1):3137. doi:10.1007/s00134-012-2715-9.

4. Benbenbishty J, Adam S, Endacott R. Physical restraint use in intensive care units across Europe: The PRICE study. Intensive Crit Care Nurs. 2018;26(5):241-245. doi:10.1016/j.iccn.2010.08.003.

5. van der Kooi AW, Peelen LM, Raijmakers RJ, et al. Use of Physical Restraints in Dutch Intensive Care Units: A Prospective Multicenter Study. Am J Crit Care . 2015;24(6):488495. doi:10.4037/ajcc2015348. 
Penultimate draft. Please cite final draft forthcoming in CHEST

6. Langley G, Schmollgruber S, Egan A. Restraints in intensive care units-A mixed method study. Intensive Crit Care Nurs. 2011;27(2):67-75. doi:10.1016/j.iccn.2010.12.001.

7. Mion LC. Physical restraint in critical care settings: will they go away? Geriatr Nurs. 2008;29(6):421-423. doi:10.1016/j.gerinurse.2008.09.006.

8. Maccioli GA, Dorman T, Brown BR, et al. Clinical practice guidelines for the maintenance of patient physical safety in the intensive care unit: Use of restraining therapies - American College of Critical Care Medicine Task Force 2001-2002. Crit Care Med. 2003;31(11):2665-2676. doi:10.1097/01.CCM.0000095463.72353.AD.

9. Park PhD, RN M, Tang PhD, RN JH-C. Evidence-Based Guideline: Changing the Practice of Physical Restraint Use in Acute Care. J Gerontol Nurs. 2007;33(2):9-16. http://myaccess.library.utoronto.ca/login?url=http://search.proquest.com/docview/204152 014?accountid=14771\%5Cnhttp://bf4dv7zn3u.search.serialssolutions.com/?ctx_ver=Z39. 88-2004\&ctx_enc=info:ofi/enc:UTF8\&rfr_id=info:sid/ProQ\%3Ahealthcompletealumnishell\&rf.

10. Bray K, Hill K, Robson W, et al. British Association of Critical Care Nurses position statement on the use of restraint in adult critical care units. Nurs Crit Care. 2004;9(5):199212. doi:10.1111/j.1362-1017.2004.00074.x.

11. Lach HW. Changing the Practice of Physical Restraint Use in Acute Care. J Gerontol Nurs. 2016;42(2):17-26. doi:10.3928/00989134-20160113-04.

12. Reduction of Patient Restraint and Seclusion in Health Care Settings Status: Revised Position Statement.; 2012.

https://www.nursingworld.org/ 4af287/globalassets/docs/ana/ethics/ps_reduction-ofpatient-restraint-and-seclusion-in-health-care-settings.pdf. Accessed August 20, 2018. 
Penultimate draft. Please cite final draft forthcoming in CHEST

13. American Academy of Nursing Choosing Wisely. www.AANnet.org. Accessed August 20, 2018.

14. Health C for D and R. Bed Rail Safety - Recommendations for Health Care Providers about Bed Rails.

https://www.fda.gov/MedicalDevices/ProductsandMedicalProcedures/HomeHealthandCo nsumer/ConsumerProducts/BedRailSafety/ucm362848.htm. Accessed August 20, 2018.

15. CMS Financial Report. https://www.cms.gov/Research-Statistics-Data-andSystems/Statistics-Trends-andReports/CFOReport/Downloads/2009_CMS_Financial_Report.pdf. Accessed August 20, 2018.

16. Choi E, Song M. Physical restraint use in a Korean ICU. J Clin Nurs. 2003;12(5):651-659.

17. Langley G, Schmollgruber S, Egan A. Restraints in intensive care units - a mixed method study. Intensive Crit Care Nurs. 2011;27(2):67-75.

18. Jiang H, Li C, Gu Y, He Y. Nurses' perceptions and practice of physical restraint in China. Nurs Ethics. 2015;22(6):652-660. doi:10.1177/0969733014557118.

19. Evans D, Wood J, Lambert L. A review of physical restraint minimization in the acute and residential care settings. J Adv Nurs. 2002;40(6):616-625. doi:10.1046/j.13652648.2002.02422.x.

20. Author.

21. Pettit P. The Basic Liberties. In: Kramer MH, ed. The Legacy of H.L.A. Hart: Legal, Political, and Moral Philosophy. Oxford University Press; 2008.

22. Rose L, Dale C, Smith OM, et al. A mixed-methods systematic review protocol to examine the use of physical restraint with critically ill adults and strategies for minimizing 
Penultimate draft. Please cite final draft forthcoming in CHEST

their use. Syst Rev. 2016;5(1):1-8. doi:10.1186/s13643-016-0372-8.

23. Hofsø K, Coyer FM. Part 1. Chemical and physical restraints in the management of mechanically ventilated patients in the ICU: contributing factors. Intensive Crit Care Nurs. 2007;23(5):249-255.

24. Hofsø K, Coyer FM. Part 2. Chemical and physical restraints in the management of mechanically ventilated patients in the ICU: a patient perspective. Intensive Crit Care Nurs. 2007;23(6):316-322.

25. Chang L-Y, Wang K-WK, Chao Y-F. Influence of physical restraint on unplanned extubation of adult intensive care patients: a case-control study. Am J Crit Care. 2008;17(5):408-15; quiz 416.

26. Birkett KM, Southerland KA, Leslie GD. Reporting unplanned extubation. Intensive Crit care Nurs. 2005;21(2):65-75. doi:10.1016/j.iccn.2004.07.012.

27. Perren A, Corbella D, Iapichino E, et al. Physical restraint in the ICU: does it prevent device removal? Minerva Anestesiol. 2015;81(10):1086-1095.

28. da Silva PSL, Fonseca MCM. Unplanned Endotracheal Extubations in the Intensive Care Unit. Anesth Analg. 2012;114(5):1003-1014. doi:10.1213/ANE.0b013e31824b0296.

29. Mion LC, Minnick AF, Leipzig RM, Catrambone CD, Johnson ME. Patient-initiated device removal in intensive care units: A national prevalence study. Crit Care Med. 2007;35(12):2714-2720. doi:10.1097/01.CCM.0000291651.12767.52.

30. Chuang ML, Lee CY, Chen YF, Huang SF, Lin IF. Revisiting unplanned endotracheal extubation and disease severity in intensive care units. PLoS One. 2015;10(10):1-10. doi:10.1371/journal.pone.0139864.

31. Rose L, Burry L, Mallick R, et al. Prevalence, risk factors, and outcomes associated with 
Penultimate draft. Please cite final draft forthcoming in CHEST

physical restraint use in mechanically ventilated adults. J Crit Care. 2016;31(1):31-35. doi:10.1016/j.jcrc.2015.09.011.

32. Chang L-C, Liu P-F, Huang Y-L, Yang S-S, Chang W-Y. Risk factors associated with unplanned endotracheal self-extubation of hospitalized intubated patients: a 3-year retrospective case-control study. Appl Nurs Res. 2011;24(3):188-192. doi:10.1016/J.APNR.2009.09.002.

33. Curry K, Cobb S, Kutash M, Diggs C. Characteristics associated with unplanned extubations in a surgical intensive care unit. Am J Crit Care. 2008;17(1):45-51; quiz 52. http://www.ncbi.nlm.nih.gov/pubmed/18158389. Accessed April 10, 2018.

34. Kang J, Lee E-N, Park EY, Lee Y, Lee MM. Emotional Response of ICU PatientsFamily toward Physical Restraints. Korean J Adult Nurs. 2013;25(2):148-156.

35. Yamamoto M, Aso Y. Placing physical restraints on older people with dementia. Nurs Ethics. 2009;16(2):192-202. doi:10.1177/0969733008100079.

36. Guenette M, Burry L, Cheung A, et al. Psychotropic drug use in physically restrained, critically ill adults receiving mechanical ventilation. Am J Crit Care. 2017;26(5):380-387.

37. Möhler R, Meyer G. Attitudes of nurses towards the use of physical restraints in geriatric care: A systematic review of qualitative and quantitative studies. Int J Nurs Stud. 2014;51(2 PG-274-288):274-288. doi:http://dx.doi.org/10.1016/j.ijnurstu.2013.10.004.

38. McCabe DE, Alvarez CD, McNulty SR, Fitzpatrick JJ. Perceptions of Physical Restraints Use in the Elderly Among Registered Nurses and Nurse Assistants in a Single Acute Care Hospital. Geriatr Nurs (Minneap). 2011;32(1):39-45. doi:10.1016/j.gerinurse.2010.10.010.

39. Freeman S, Hallett C, McHugh G. Physical restraint: experiences, attitudes and opinions 
Penultimate draft. Please cite final draft forthcoming in CHEST

of adult intensive care unit nurses. Nurs Crit Care. 2016;21(2):78-87. doi:10.1111/nicc.12197.

40. Titler MG, Shever LL, Kanak MF, Picone DM, Qin R. Factors Associated With Falls During Hospitalization in an Older Adult Population. Res Theory Nurs Pract. 2011;25(2):127-152. doi:10.1891/1541-6577.25.2.127.

41. Bower FL, McCullough CS, Timmons ME. A Synthesis of What We Know About the Use of Physical Restraints and Seclusion with Patients in Psychiatric and Acute Care Settings: 2003 Update. Worldviews Evidence-based Nurs Present Arch Online J Knowl Synth Nurs. 2004;E10(1):1-29. doi:10.1111/j.1524-475X.2003.00001.x.

42. Yamamoto M, Izumi K, Usui K. Dilemmas facing Japanese nurses regarding the physical restraint of elderly patients. Japan J Nurs Sci. 2006;3(1):43-50. doi:10.1111/j.17427924.2006.00056.x.

43. Berzlanovich AM, Schöpfer J, Keil W. Todesfälle bei gurtfixierungen. Dtsch Arztebl Int. 2012;109(3):27-32. doi:10.3238/arztebl.2012.0027.

44. Hatchett C, Langley G, Schmollgruber S. Psychological sequelae following ICU admission at a level 1 academic South African hospital. South African J Crit Care. 2010;26:52-58.

http://ovidsp.ovid.com/ovidweb.cgi?T $=\mathrm{JS} \& C S C=\mathrm{Y} \& \mathrm{NEWS}=\mathrm{N} \& \mathrm{PAGE}=$ fulltext\&D=eme d10\&AN=2012510856\%3C348.\%5Cn\%3E.

45. Demir A. Nurses' Use of Physical Restraints in Four Turkish Hospitals. J Nurs Scholarsh. 2007;39(1):38-45. doi:10.1111/j.1547-5069.2007.00141.x.

46. Tolson D, Morley JE. Physical Restraints: Abusive and Harmful. J Am Med Dir Assoc. 2012;13(4):311-313. doi:10.1016/j.jamda.2012.02.004. 
Penultimate draft. Please cite final draft forthcoming in CHEST

47. Jones C, Bäckman C, Capuzzo M, Flaatten H, Rylander C, Griffiths RD. Precipitants of post-traumatic stress disorder following intensive care: A hypothesis generating study of diversity in care. Intensive Care Med. 2007;33(6):978-985. doi:10.1007/s00134-0070600-8.

48. Mathisen L, Martin B. Use of physical restraints in adult critical care: a bicultural study. Am J Crit Care. 2005;14(2).

49. Davydow D, Gifford J. Posttraumatic Stress Disorder in General Intensive Care Unit Survivors: A Systematic Review. Gen Hosp .... 2008;30(5):421-434. doi:10.1016/j.genhosppsych.2008.05.006.Posttraumatic.

50. Chuang Y, Huang H. Nurses' feelings and thoughts about using physical restraints on hospitalized older patients. J Clin Nurs. 2007;16(3):486-494.

51. Hevener S, Rickabaugh B, Marsh T. Using a Decision Wheel to Reduce Use of Restraints in a Medical-Surgical Intensive Care Unit. Am J Crit Care. 2016;25(6):479-486. doi:10.4037/ajec2016929.

52. Antonelli MT. Restraint management: moving from outcome to process. J Nurs Care Qual. 2008;23(3):227-232. doi:10.1097/01.NCQ.0000324587.53719.2f.

53. Johnson K, Curry V, Steubing A, et al. A non-pharmacologic approach to decrease restraint use. Intensive Crit Care Nurs. 2016;34:12-19. doi:10.1016/j.iccn.2015.08.004.

54. Cosper P, Morelock V, Provine B. Please release me restraint reduction initiative in a health care system. J Nurs Care Qual. 2015;30(1):16-23. doi:10.1097/NCQ.0000000000000074.

55. Mion LC, Fogel J, Sandhu S, et al. Outcomes following physical restraint reduction programs in two acute care hospitals. Jt Comm J Qual Improv. 2001;27(11):605-618. 
Penultimate draft. Please cite final draft forthcoming in CHEST

56. Kong E-H, Song E, Evans LK. Effects of a Multicomponent Restraint Reduction Program for Korean Nursing Home Staff. J Nurs Scholarsh. 2017;49(3):325-335. doi:10.1111/jnu.12296.

57. Hurlock-Chorostecki C, Kielb C. Knot-So-Fast: A learning plan to minimize patient restraint in critical care. Can Assoc Crit Care Nurses. 2006;17(3):12-18.

58. Strout TD. Perspectives on the experience of being physically restrained: An integrative review of the qualitative literature. Int J Ment Health Nurs. 2010;19(6):416-427. doi:10.1111/j.1447-0349.2010.00694.x.

59. Jones C, Bäckman C, Capuzzo M, Flaatten H, Rylander C, Griffiths RD. Precipitants of post-traumatic stress disorder following intensive care: a hypothesis generating study of diversity in care. Intensive Care Med. 2007;33(6):978-985. doi:10.1007/s00134-0070600-8.

60. Hatchett C, Langley G, Schmollgruber S. Psychological sequelae following ICU admission at a level 1 academic South African hospital. South African J Crit Care. 2010;26(2):52. doi:10.7196/sajcc.104.

61. De Bellis A, Mosel K, Curren D, Prendergast J, Harrington A, Muir-Cochrane E. Education on physical restraint reduction in dementia care: a review of the literature. Dementia. 2013;12(1):93-110. doi:10.1177/1471301211421858.

62. Enns E, Rhemtulla R, Ewa V, Fruetel K, Holroyd-Leduc JM. A controlled quality improvement trial to reduce the use of physical restraints in older hospitalized adults. $J$ Am Geriatr Soc. 2014;62(3):541-545. doi:10.1111/jgs.12710.

63. Cosper P, Morelock V, Provine B. Please release me: restraint reduction initiative in a health care system. J Nurs Care Qual. 2015;30(1):16-23. 
Penultimate draft. Please cite final draft forthcoming in CHEST

doi:10.1097/NCQ.0000000000000074.

64. Chang L-C, Liu P-F, Huang Y-L, Yang S-S, Chang W-Y. Risk factors associated with unplanned endotracheal self-extubation of hospitalized intubated patients: a 3-year retrospective case-control study. Appl Nurs Res. 2011;24(3):188-192.

doi:10.1016/j.apnr.2009.09.002.

65. Lane E, Kuzow H, Manguera A, Perry R, Mansour M. 1142: Mitts before wrists: safety mitts reduce restraint usage and can decrease unplanned self-extubations. Crit Care Med. 2016;44(12).

https://journals.lww.com/ccmjournal/Fulltext/2016/12001/1142__MITTS_BEFORE_W RISTS_SAFETY_MITTS_REDUCE.1102.aspx. 